\title{
In COLLISIONS AND COOPERATION THEY LEARNT: FINDING A Balance Between Online ANd In Person Teaching ToOlS
}

\author{
Peter Eliot Weiss, Jason Bazylak, Susan McCahan, and Ken Tallman \\ University of Toronto \\ weissp@ecf.utoronto.ca jbazylak@mie.utoronto.ca mccahan@mie.utoronto.ca k.tallman@utoronto.ca
}

\begin{abstract}
As our courses implement more online learning tools, we are facing both the opportunities and the challenges that such tools present. On the one hand, students can watch and re-watch streamable and downloadable lectures, in their own time and at their own pace, to get more benefit out of course material than they might in a single, in-person exposure. Moreover, by providing not only captured scheduled lectures, but also additional custom created lectures, we are able to expand our teaching opportunities in order to go into greater detail on topics relevant to students with particular interests or needs.

At the same time as we have been moving toward online teaching tools, we have been developing more creative personal teaching methods. In our first year course, we introduced seminars, unusual for engineering education at the undergraduate level. The seminars get students used to learning through independent reading and small group discussion, facilitated by an expert. In a second year design course, instead of attending tutorials of 30 students, teams meet for half an hour a week with a Project Manager who is also their Communication Instructor. These deeply personal meetings both monitor the progress of their design and allow for individualized instruction on design documents.

The question we are exploring here is whether we can use Marshall McLuhan's concept of extending into technology to understand how in-person, interactive teaching modes balance the effects of on-line and remote methods. The idea of the in-person, physical dimension of learning is reflected in the title of this paper, which quotes The History of the World by J.M. Roberts. He suggests that what generated "civilization" out of roughly organized communities, was a combination of a critical mass - a certain, unstated number of settled humans and movement, the addition of different humans from different places. It was both physical presence and interaction that created the basis for the kinds of astounding developments that led to writing, art, complex government and justice systems. Once certain numbers were achieved, civilization was enabled "by throwing
\end{abstract}

together peoples of different tradition. In collision and cooperation they learnt from one another and so increased the potential of their society." (62)

We have been intuitively moving forward on these two fronts: implementing new technological teaching tools, and developing innovative ways to balance these impersonal methods by "throwing together" students from all over the world and instructors at every level, from Teaching Assistants to Professors. We are now seeking a clearer understanding of how these forces balance, enable and/or augment one another.

Keywords: McLuhan, teaching tools, on-line learning, tutorial design

\section{INTRODUCTION}

The post-secondary learning environment is changing radically from a lecture hall or classroom which privileges the "teacher" by placing her/him at the centre of the room, where she or he is the focus of attention, to a virtual landscape in which the learner may be accessing information from a multiplicity of sources, only one of which is provided by the teacher in the class environment. These changes may seem threatening. Certainly, they are challenging. It is difficult to know how best to approach lectures in which students are using a variety of devices for everything from taking notes and instantly googling concepts that are unfamiliar to messaging and playing games. One wonders whether or not they should be "paying more attention" or whether they are actually appropriately adjusting themselves to the pace of information in the lecture. What this paper intends to explore is the idea that students in this environment are behaving naturally, as beings who are extended into technological devices. Because they are extended into devices, these devices are, in a way, inseparable from their bodies; their use requires a rebalancing of the person's senses. Can this rebalancing be facilitated by person-toperson interactions, which in turn offer unique learning opportunities? 
This idea of extending into technology and the subsequent need for rebalancing was explored by Marshall McLuhan in Understanding Media: The Extensions of Man (sic) [1]. He suggests that a technology "extends" human capabilities and that, in doing so, requires the human to rebalance their senses. An analogy for this concept could be the idea of a lever, which extends human strength (literally the human arm) but requires the human to take a position which balances the force being exerted on the lever. Should the resistance suddenly subside, the person using the lever would fall forward.

When the extensions are sensory, the balances are not so visible. McLuhan, rather shockingly, suggests that electricity extends the nervous system outside of the human body. The analysis of this idea, however, is informative. Electricity, which allows for artificial light and rapid information transfer, creates technologically produced levels of "stimulation" that require the human to rebalance her/his sense ratios. With technologies that extend human awareness, humans, in terms of their senses, begin to inhabit more than one place. The consciousness of the person talking on a cellphone in an automobile, whether hand-held or not, is both in the automobile and in the virtual location of the conversation. The result is a necessary reallocation of sensory resources, such as peripheral awareness [2].

One might argue that those of us who use any technology that extends our consciousness, voice or memory, are in a constant state of having to rebalance our senses. We constantly have to change our physical, emotional and intellectual position in order to balance stimulation that we experience through our extensions. Even the act of turning off the device will require rebalancing since turning it off will change the forces that were working on us and that we have already adjusted to. As with the lever, if resistance gives way suddenly, a person can tip over. That is why telling someone to turn off their cell-phone does not immediately enable that person to pay attention. The point is, whether the devices are on or off, the person who uses the devices is still extended into them and is still having to balance and rebalance due to their stimulation or the removal of that stimulation.

On one side of this dynamic situation, is the virtual world and on the other is the human world. The virtual world, for all its convenience and recreational interactivity, is a place of fixed relationships - the information remains implacably what it is, programs will do only what they are programmed to do. The human who has varying perceptions and needs can be frustrated with a program's inability to respond to subtle adjustments in the query.

The human world, on the other hand, can be one of great flexibility and multidimensional communication.
The learner communicates with the faculty member in words, tone and body language and the faculty member can respond to any aspect of the inquiry, especially when the questioner is confused. It is obvious that a conventional lecture, moving along its preplanned, predetermined path, does not offer any greater flexibility than a programmed website. Whereas other learning environments can be created that do have flexibility.

In 2003, L. Dee Fink, in the influential book Creating Significant Learning Experiences, shifted the educational paradigm from "teaching" students to "creating learning experiences" or multidimensional learning environments [3]. In the new paradigm, the "teacher" is no longer an "expert" transferring "knowledge" to students who seem to be empty vessels waiting to be filled. Rather, student learning results from a complex negotiation between a faculty member with certain knowledge, skills and powers and a learner who has a different set of knowledge, skills and powers.

It is vital, however, to recognize that the site of learning has become a place of "sharing" of information between equal parties - the learner and the faculty member. It is this idea of "sharing" that distinguishes the post-Fink negotiation of learning from other interactive teaching methods which still privilege the teacher. Even the Socratic method, valued for the fact that it does not dump information into student "empty-vessels," and seeks, instead, to "lead" the student to understanding through questions, still privileges the teacher who on some level "knows" the answer or the end place to which the student is being "led." Shared sites of learning allow for insight to emerge from anyone and for new information to be found by anyone. Old information that is shared can be found to be useful by all or may be found to be outmoded. In this paradigm, faculty members learn from students, just as students learn from faculty members. Each group has a different set of responsibilities and these must be made clear in order for the learning environment to function.

\section{PROVIDING VIRTUAL LEARNING TOOLS}

Our implementation of shared learning environments does not follow a cause-and-effect sequence in relation to our implementation of online learning materials. The two sides of our teaching evolved in some cases separately, in some cases simultaneously. The question we are facing now is where the two sides can work to balance one another.

\subsection{First Year Design-Communication Course}

Creating shared learning environments preceded the use of online tools in our first year cycle of design courses Engineering Strategies and Practice. There are two related 
courses - one in the fall and one in the winter term. Enrollment is around 950 students and the course is delivered through lectures and tutorials.

Lectures have evolved, over time, to include some interactivity through iClicker questions and questions texted to the lecturer from student cellphones. The questions are received by a teaching assistant who passes them to the lecturer at appropriate breaks. Over the last year, lectures have also expanded out of the lecture hall. They are video recorded and made available online. Plus, additional on-line only lectures on selected topics, often detailed instructions for the assignments, have also been provided. The online resources enable students who miss lectures to keep up or catch up; they provide additional information that might be of interest to only a part of the class. For complex concepts or for building English language skills, online resources allow students to repeat a section of a lecture until they feel secure in their understanding. Nevertheless, lectures remain somewhat distant, but more personal interactions occur in tutorials.

From its inception, this course has used tutorials in two unique ways: either for structured team work or for seminars. In the first half of first term, and in all of second term, the tutorial sessions give students an opportunity to work in teams to practice the design process. In first term, they work on a fictitious project, but in second term, they have an actual client from the community. Every tutorial session has an agenda, which guides student teams through activities and models agenda is use in business. In first term, the agendas are provided; in second term, the student teams must draw up their own.

In both the fall and winter term, Teaching Assistants supervise the tutorials. In the winter term, a project manager is also present to monitor progress on the students' projects. Students seem to develop strong relationships with their TAs, rating them favourably and commenting frequently on how they help students develop understanding of the course material.

In the second half of the fall term, tutorial sessions take an approach to learning unique in engineering: seminars, which are more familiar in upper levels, honours and graduate courses in the humanities [4]. In this mode of learning, a student is given readings to prepare for the session. There is typically a central question, or problem that acts as the focus of the seminar. Supporting questions are given and the students are expected to formulate preliminary answers in preparation for class. In the session, the group, typically 25 students, discusses the readings. Students may also, individually, give short presentations. This instructional method has proven to be very successful in ESP and the students have given the seminars the highest ratings of any element in the course [5].

\subsection{A Second Year Design-Communication Course}

A second year course in design and communication in the Edward Rogers Senior Department of Electrical and Computer Engineering provides a balance of learning through online resources and personal interaction with peers and faculty members in an intimate tutorial setting. The tutorials offer not only a highly personal level of contact and interaction but, more important, they provide a fundamentally different type of learning experience. Rather than information-driven instruction, with clearly delineated boundaries between instructor and student and clearly "testable" content, the tutorials, in the post-Fink tradition, are learning communities, committed to the values of working within a community of practice.

Thus, the conventional form of the tutorial is altered so that the tutorial time becomes usable for the student, to work on the term long project according to the student team's own agenda. The only requirement is that each team meets with a Communication Instructor (CI), in the role of Project Manager, for a half an hour each week. For some teams, this half hour takes part of their scheduled tutorial time. For other teams, it is scheduled at a different, mutually agreeable time.

According to Scardamalia and Bereiter [6], the goal of a learning community is to advance the collective knowledge of the group such that each member increases his or her individual knowledge. Such communities clearly benefit from a diversity of skills among their members and from an internal support system in which each member aids the development of the other team members' skills.

Though communities usually have leaders, many scholars agree that learning communities can and should be negotiated, with all participants determining the goals and the norms for the community [7]. Though students may not always acknowledge or desire this negotiation, the ECE297 tutorial meetings quickly prompt students to readjust their expectations. This is so for two reasons. First, each student is required to lead a meeting on a revolving basis, giving the students considerable responsibility in setting the goals and the agenda for each session; and, second, the CIs who oversee the tutorials are not formally trained as engineers, requiring the students to take a lead role when discussing their projects in technical terms. Though the CIs are expected to be familiar with the course's technical requirements and be capable of answering technical questions, they are not the experts of this domain. These two factors help to ensure that all members of the community are committed to collective knowledge, and leadership shifts frequently to suit the needs of the moment.

Bielaczyc and Collins [8] emphasize the ways in which learning communities foster life-long learning, and the 
ECE297 tutorials certainly help students develop these types of "durable" skills. For instance, though the teams establish goals at the beginning of term, they recognize that they must revisit and adjust these goals regularly as the term progresses. This type of insight is only possible with sustained regular meetings and is the type of knowledge a student can easily transfer to the next project in which he or she will be involved.

In fact, "lifelong learning" is probably the most important lesson the tutorials support. The course has no textbook but in the detailed assignment instructions links are provided for online resources. The students are encouraged to find others, to explore, utilize trial-anderror methods, and learn on their own. The tutorials proved an environment in which students can discuss their own ideas or ideas they have found through research. The CI, often having worked in the course before, but still not an expert in coding, provides an intelligent response, questioning ideas in a way that enables students to build their ability to communicate their understanding and to clarify that understanding.

As the term progresses, it is clear that a potent form of reciprocal instruction is developing. Reciprocity, clearly at the root of learning communities and mediated learning, is key in developing the students' learning skills. The main goal of the instructor $(\mathrm{CI})$ in this situation is, thus, to mediate. As Kozulin emphasizes, the mediator's job is not to solve problems for the students, but rather to provide them with the scaffolding and strategies to do so themselves. As Kozulin notes, "The problem at hand is only an excuse to involve the mediator with the learner's thinking process" [9]. This "involvement" can take many forms, but it generally depends upon two factors: 1) reciprocity, the instructor's and the student's ability and willingness to exchange roles, such that students are able to find solutions and articulate these solutions themselves, and 2) mediation of meaning, the instructor's ability to interpret the student's learning such that the students can navigate the journey independently themselves the next time.

Learners at all levels benefit from mediated learning, but mediated learning perhaps has particular relevance to our 2nd year students. These students, beginning the process of moving from novices to experts in their fields, are in need of tools to build their emerging "expert" identities. The CIs, non-experts in software programming, provide the students an authentic opportunity to develop these "expert" identities. Here, in a sense, the roles are reversed: the students must find strategies to explain specifications and concepts to a manager who has a high level view of the project, but does not know what the students know and is invested in finding that out. By practicing their expert identities, the students make a crucial leap toward mastering the learning process.
The CIs must certainly know some of the technical content; otherwise, the students will rightly discredit them. Most CIs, in fact, find that after teaching in the course once, they have adequate technical understanding for subsequent terms. Though they may not know the code requirements as well as the students, they understand enough about the software development process to be capable of evaluating content. Furthermore, as noted, the tutorials are not really about learning content; they are about learning community, learning how to learn within a community of learners, and it is this that the instructors must have the skills to facilitate.

\section{CONSTRUCTING KNOWLEDGE IN A DIVERSE COMMUNITY}

Another dimension of this shared learning space comes from the multi-national nature of our student body. Little could McLuhan have envisioned, when he coined the term "Global Village" in 1962 [10], the virtual profile universities have developed beyond their campuses and countries. Students everywhere can visit on-line and apply to universities anywhere. The result, in a shared learning environment, is a "collision of cultures" that must learn how to cooperate.

As Northrop Frye has pointed out [11], language differences, by their nature, reflect and produce perceptual differences. The fact that our shared learning space conducts its discussions in English does not (and should not) eradicate the perceptual differences that students are bringing to the process of developing knowledge. These differences are an asset. J.M. Roberts [12] suggests, in describing the evolution of early cultures, that advancement occurred as the result of migration of peoples from one area to another. "In collision and cooperation they learnt from one another and so increased the potential of their societies." (page 63) As we all attempt to negotiate the changing economic, intellectual and cultural environments of our current era, this "collision and cooperation" may be extremely helpful.

\section{CONCLUSION}

What our observations suggest is that while providing course instruction on line is probably not only highly desirable, but also inevitable, planned expansion into virtual teaching can be balanced by increased attention to in-person shared learning environments. On-line resources enable students to keep up or catch up, to get additional information or improve language skills, but human intervention has been seen to be valuable - and valued in moderating how students process the information they are gathering in order to turn it into useful knowledge. Online resources can both provide answers to problems of 
constrained resources and free up some human resources to enable more in-person learning situations. In a shared learning environment, students and faculty members alike are able to advance in their knowledge and understanding, a highly desirable prospect as we all face the uncertainties of the volatile data age.

\section{References}

[1] Marshall McLuhan, Understanding Media: The Extensions of Man. New York: McGraw-Hill, 1964, $318 \mathrm{pp}$.

[2] W.C. Maples, Wes DeRosier, Richard Hoenes, Rodney Bendure, and Sherl Moore. "The effects of cell phone use on peripheral vision." Optometry, vol. 79, pp. 36-42, 2008.

[3] L. Dee Fink, Creating Significant Learning Experiences. Hoboken, NJ: Wiley, 2003, 295 pp.

[4] Jason Bazylak and Susan McCahan. "Interactive First-Year Engineering Seminar Series." Proc. CEEA Canadian Engineering Education Conf., (Kingston, ON; 79 June 2010), 6 pp., 2010.

[5] Susan McCahan, Peter Weiss, Kimberly Woodhouse, Robert Andrews, Philip Anderson, Mark Kortschot, and Sandy Romasto. "Alan Blizzard Plenary," Society for Teaching and Learning in Higher Education, Edmonton, Alberta, 2007.

[6] M. Scardamalia and C. Bereiter, "Computer support for knowledge-building communities," Journal of the Learning Sciences [Online].Volume 3, Issue 3, 1994, pp. 265-283. Accessed May 14, 2012. Available: http://www.tandfonline.com/doi/abs/10.1207/s153278 $\underline{09 \mathrm{j} l \mathrm{~s} 0303 \quad 3}$

[7] S.A. Barab and T. Duffy, "From practice fields to communities of practice" in Theoretical Foundations of Learning Environments. [Online]. D. Jonassen and S. Land, Eds. Mahwah, NJ: Lawrence Erlbaum Associates, 2000, pp. 25-55. Accessed May 14, 20212. Available: http://goo.gl/UqpZa

[8] K. Bielaczyc and A. Collins, "Learning communities in classrooms: A reconceptualization of educational practice" in Instructional-Design Theories and Models: A New Paradigm of Instructional Theories. Volume 2. [Online]. Charles M. Reigeluth, Ed. Mahwah, NJ: Lawrence Erlbaum Associates, 1999, pp. 269-277. [ISBN 0-8058-2859-1]. Accessed May 13, 2012. Available: http://goo.gl/eNvtj

[9] A. Kozulin, "Psychological tools and mediated learning," Vygotsky's Educational Theory in Cultural Context. [Online]. Alex Kozulin, Boris Gindis, Vladimir S. Ageyev, and Suzanne M. Miller, Eds. Cambridge University Press, Cambridge, United Kingdom, 2003, pp. 15-38. [ISBN 0-521-82131-2]. Accessed May 14, 2012. Available: http://goo.gl/yQ1QD

CEEA12; Paper 028

Winnipeg, MB; June 17-20, 2012

-5 of $5-$
[10] Marshall McLuhan. The Gutenberg Galaxy: The Making of Typographic Man. Toronto: University of Toronto Press, 2011, 332 pp.

[11] Northrop Frye. The Educated Imagination. Toronto: Anansi, 2002, 80 pp.

[12]J.M. Roberts. The Pelican History of the World. London: Penguin, 1988, 1033 pp. 